Published in final edited form as:

Clin Gastroenterol Hepatol. 2007 March ; 5(3): 394-267.

\title{
THE UTILITY OF AFP-L3\% IN THE DIAGNOSIS OF HEPATOCELLULAR CARCINOMA: EVALUATION IN A U.S. REFERRAL POPULATION
}

\begin{abstract}
Apinya Leerapun ${ }^{1}$, Sri V. Suravarapu ${ }^{2}$, John P. Bida ${ }^{3}$, Raynell J. Clark ${ }^{4}$, Elizabeth L. Sanders $^{4}$, Teresa A. Mettler ${ }^{1}$, Linda M. Stadheim ${ }^{1}$, Ileana Aderca ${ }^{1}$, Catherine D. Moser ${ }^{1}$, David M. Nagorney ${ }^{5}$, Nicholas F. LaRusso ${ }^{1}$, Piet C. de Groen ${ }^{1}$, K. V. Narayanan Menon ${ }^{1}$, Konstantinos N. Lazaridis ${ }^{1}$, Gregory J. Gores ${ }^{1}$, Michael R. Charlton ${ }^{1}$, Rosebud 0. Roberts $^{2}$, Terry M. Therneau ${ }^{3}$, Jerry A. Katzmann ${ }^{4}$, and Lewis R. Roberts ${ }^{1}$

1 Miles and Shirley Fiterman Center for Digestive Diseases, Department of Internal Medicine, Mayo Clinic College of Medicine, 200 First Street SW, Rochester, MN 55905
\end{abstract}

2Division of Epidemiology, Department of Health Sciences Research, Mayo Clinic College of Medicine, 200 First Street SW, Rochester, MN 55905

3Division of Biostatistics, Department of Health Sciences Research, Mayo Clinic College of Medicine, 200 First Street SW, Rochester, MN 55905

4Division of Laboratory Medicine, Department of Laboratory Medicine and Pathology, Mayo Clinic College of Medicine, 200 First Street SW, Rochester, MN 55905

5Division of Gastroenterologic and General Surgery, Department of Surgery, Mayo Clinic College of Medicine, 200 First Street SW, Rochester, MN 55905

\section{Abstract}

Background \& Aims-The percentage of alpha-fetoprotein (AFP) binding to Lens culinaris agglutinin (AFP-L3\%) is proposed as a diagnostic and prognostic marker for hepatocellular carcinoma (HCC). We evaluated the utility of AFP-L3\% for diagnosis of HCC in a U.S. referral population.

Methods-This retrospective study included 272 patients: 166 with HCC and 106 with benign liver disease (chronic liver disease, $C L D=77$, benign liver mass $=29$ ). AFP-L3\% was measured using the Wako LiBASys clinical autoanalyzer.

Results-AFP-L3\% levels are not reported for total AFP <10, and all patients with AFP $>200$ had HCC; thus AFP-L3\% was non-informative for these patients. In patients with total AFP of 10-200 $\mathrm{ng} / \mathrm{ml}$, an AFP-L3\% cut-off of $>10 \%$ had a sensitivity of $71 \%$ and specificity of $63 \%$ for diagnosis of HCC. An AFP-L3\% cut-off of $>35 \%$ had a reduced sensitivity of 33\%, but an increased specificity of $100 \%$ for diagnosis of HCC. The high specificity AFP-L3\% cut-off of 35\% allowed the confident

Address correspondence to: Lewis R. Roberts, MD PhD, Miles and Shirley Fiterman Center for Digestive Diseases, Mayo Clinic College of Medicine, 200 First Street SW, Rochester, MN 55905, Email: Roberts.lewis@ mayo.edu, Phone: 507284 0686, Fax: 5072840762 Author contributions: Conception and design of the study: MRC, JAK, and LRR

Generation of data: AL, SVS, RJC, ELS, TAM, LMS, IA, and CDM

Collection, assembly, analysis and interpretation of data: AL, SVS, JPB, DMN, NFL, PCD, KVNM, GJG, ROR, TMT, and LRR

Drafting or revision of the manuscript: AL, SVS, JPB, ROR, TMT, and LRR

Approval of the final version of the manuscript: All authors.

Publisher's Disclaimer: This is a PDF file of an unedited manuscript that has been accepted for publication. As a service to our customers we are providing this early version of the manuscript. The manuscript will undergo copyediting, typesetting, and review of the resulting proof before it is published in its final citable form. Please note that during the production process errors may be discovered which could affect the content, and all legal disclaimers that apply to the journal pertain. 
diagnosis of an additional $10 \%$ of HCCs that were not diagnosed using the total AFP cut-off of 200 $\mathrm{ng} / \mathrm{ml}$. After adjustment for total AFP, no association was observed between AFP-L3\% and tumor size, stage, vascular invasion, grade, or survival.

Conclusions-Patients with indeterminate total AFP values of 10-200 ng/ml present a diagnostic dilemma. We found that an AFP-L3\% >35\% has $100 \%$ specificity for HCC in these patients. AFP$\mathrm{L} 3 \%$, used in combination with AFP, may be a clinically useful adjunct marker for diagnosis of HCC.

\section{Keywords}

Alpha fetoprotein; AFP-L3\%; hepatocellular carcinoma

\section{INTRODUCTION}

Hepatocellular carcinoma (HCC) is the third leading cause of death from cancer worldwide. The incidence of HCC in the United States has doubled in the past 25 years, primarily due to the increasing prevalence of hepatitis $\mathrm{C}$ virus infection ${ }^{1}$. When diagnosed at an early stage, treatment of hepatocellular carcinoma with liver transplantation or surgical resection can be curative. However, in spite of effective therapies for early stage HCC's and efforts at early diagnosis of HCC through screening of patients at risk for this cancer, most HCC's are diagnosed at an advanced stage. In the United States, less than $15 \%$ of patients diagnosed with HCC are eligible for liver transplantation or surgical resection with curative intent ${ }^{23}$. Therefore, there is an urgent need for improved methods of screening and surveillance of individuals at risk for HCC. Early diagnosis of HCC is difficult, in part because (i) HCCs are typically asymptomatic until the tumor is large or infiltrating, (ii) the standard serum screening test, alpha fetoprotein (AFP) has poor sensitivity for the detection of small tumors, and (iii) the AFP is often elevated in patients with chronic hepatitis $\mathrm{C}$ virus infection in the absence of HCC. Although it has relatively poor sensitivity and specificity as a surveillance test, the serum AFP, used in combination with serial liver ultrasound examination, is a de facto standard for risk stratification, screening and surveillance for HCC.

The lens culinaris agglutinin (LCA)-reactive alpha-fetoprotein percentage of total AFP concentration [(AFP-L3 / total AFP) $\times 100$ ] or AFP-L3\% has been used as a marker for early diagnosis, for assessment of therapeutic effects, and for predicting the prognosis of $\mathrm{HCC}^{4-8}$. The AFP-L3 isoform has been reported to be more specific for the diagnosis of HCC than total AFP level ${ }^{9}$. It has also been shown to be associated with more aggressive HCC's, and to predict a worse outcome ${ }^{10}$. Recent reports also suggest that it is useful for predicting the risk of development of HCC in patients with chronic liver disease. With recent progress in the identification and characterization of new serum markers for hepatocellular carcinoma such as gp73 and glypican 3, and also with recent improvements in the assays for the AFP-L3\% fraction and des gamma carboxyprothrombin, it is probable that future efforts at surveillance of patients with cirrhosis who are at risk for $\mathrm{HCC}$ will use a panel of serum markers. In order to achieve optimal results with a combination of markers, it is important that each marker be carefully evaluated to establish its potential place in the panel.

The aim of our study was to examine the diagnostic utility and performance characteristics of the AFP-L3\% in a U.S. referral practice population using the Wako LiBASys clinical autoanalyzer. 


\section{MATERIALS and METHODS}

\section{Study participants}

Written informed consent and blood samples were obtained from 272 adult patients evaluated for HCC, chronic liver disease or benign liver masses between September 1993 and July 2004 as part of two IRB approved registries. Cases were selected for whom a specimen was available that had been drawn after diagnosis of HCC but before any therapy. Clinical and laboratory information at the time of diagnosis were retrospectively ascertained from the medical record. Of the 272 patients, 166 had HCC and 106 had benign liver disease (chronic liver disease = 77 , benign liver mass $=29$ ). A proportion of the patients were eligible for liver transplantation for chronic liver disease or HCC. The diagnosis of HCC was based on either histopathology or on non-invasive criteria. The non-invasive diagnosis of HCC was established based on the following modified EASL 2000 criteria, with a modified total AFP cut-off of $>200 \mathrm{ng} / \mathrm{ml}$ corresponding to the current UNOS criteria: 1) presence of cirrhosis and a newly developed enhancing lesion $>2 \mathrm{~cm}$ found by two or more imaging modalities (including ultrasound, contrast CT, contrast MRI, and angiography);2) presence of cirrhosis and a newly developed enhancing lesion $>2 \mathrm{~cm}$ found by one imaging modality (including contrast CT, contrast MRI, and angiography) and a total AFP $>200 \mathrm{ng} / \mathrm{ml}$. Of the 166 patients with $\mathrm{HCC}, 134$ had histologic or clinical evidence of cirrhosis. Cirrhosis was diagnosed by histology in 100 of the 134 (75\%). When liver biopsy was unavailable the diagnosis of cirrhosis was based on clinical and imaging criteria - evidence of clinically significant portal hypertension with splenomegaly, thrombocytopenia, ascites, esophageal or gastric varices, or portal hypertensive gastropathy.

Fifty-two of the HCC patients underwent liver transplantation, 25 had a surgical resection, 8 had radiofrequency ablation, 7 had percutaneous ethanol injection, 36 had transarterial chemoembolization, and 3 received systemic chemotherapy.

The medical record for each study participant was reviewed in detail to ascertain the medical history, physical and laboratory findings. The age at diagnosis of chronic liver disease and HCC, tumor characteristics at diagnosis of HCC (size, number of nodules, micro- or macrovascular invasion, histologic grade) and tumor stage (based on the American Joint Committee on Cancer revised scoring system) were abstracted. Demographic and anthropometric data including age, sex, race, weight, height, and body mass index $\left(B M I=\mathrm{kg} / \mathrm{m}^{2}\right)$ were also abstracted. Laboratory findings abstracted included liver biochemistries (AST, ALT, alkaline phosphatase, total and direct bilirubin, albumin), platelet count, prothrombin time, creatinine, hepatitis B and C serologies, fasting glucose, total, LDL and HDL cholesterol, and triglycerides. The MELD score at the time of diagnosis was calculated using the standard formula ${ }^{11}$. Histopathology slides for patients who underwent surgical resection or needle biopsy were reviewed by a liver pathologist. HCC grade was assigned on a scale from 1 (most differentiated) to 4 (least differentiated). The presence or absence of microvascular invasion was recorded. Patient vital status (dead or alive) was ascertained from the medical record in January 2006.

\section{Measurement of AFP-L3\%}

Samples were obtained at the time of diagnosis or at the time when patients were first seen at Mayo Clinic prior to treatment, and stored at $-70^{\circ} \mathrm{C}$. The total AFP and AFP-L3\% were measured by a liquid-phase binding assay on the Wako LiBASys clinical auto analyzer (Wako Pure Chemical Industries, Ltd. Osaka, Japan) ${ }^{12}$. The typical inter-assay variance for this test, expressed as the coefficient of variance, is between 2.8\% and 13.4\% for AFP-L3\% and 2.6\% and $4.6 \%$ for AFP concentration ${ }^{12}$. Assay results correlate well with those of the commercially available lectin-affinity electrophoresis for AFP-L3\% ( $\mathrm{r}=0.984)$ and with the radioimmunoassay method for total AFP concentration ( $\mathrm{r}=0.999)$. Thus, this method 
simultaneously yields quantitative results for both AFP-L3\% and total AFP concentration ${ }^{12}$. The LiBASys autoanalyzer has a lower limit of detection for total AFP concentration of 0.8 $\mathrm{ng} / \mathrm{ml}$ and for AFP-L $3 \%$ of $0.5 \%$. If AFP-L 3 is detected in the sample, the system only provides a reliable value of AFP-L3\% for samples when the total AFP concentration is $=10 \mathrm{ng} / \mathrm{ml}$. For samples with total AFP of $>300,000 \mathrm{ng} / \mathrm{ml}$, we elected not to assess AFP-L3\% because of the need for multiple sequential dilutions of the sample. Hence, AFP-L3\% results were classified as: unmeasurable when total AFP was $<0.8 \mathrm{ng} / \mathrm{ml}$ (U); high when total AFP was $>300,000 \mathrm{ng} /$ $\mathrm{ml}(\mathrm{H}$; where relevant, the five $\mathrm{H}$ samples were assigned an AFP-L3\% of $100 \%$ during the analysis); not reported when total AFP was between 0.8 and $10 \mathrm{ng} / \mathrm{ml}$ (NR) and AFP-L3\% was a measurable value $>0.5 \%$; and not detected when total AFP was $=0.8 \mathrm{ng} / \mathrm{ml}$ but AFP-L3\% was $<0.5 \%$ (ND).

\section{Statistical analysis}

The descriptive characteristics of HCC and CLD patients were compared using the Wilcoxon rank sum test or the Chi square test. The characteristics of patients with a benign liver mass were also determined to provide information on the normal estimates. The primary objective of the study was to determine the additional information derived from an AFP-L3\% measurement for a diagnosis of HCC, given a total AFP value. Thus, analyses were performed stratified by three categories of total AFP: $<10,10-200$, and $>200 \mathrm{ng} / \mathrm{ml}$. These subcategories of total AFP were based on the optimal cutpoint of approximately $10 \mathrm{ng} / \mathrm{ml}$ determined from previous studies ${ }^{13}$ and the high specificity cutpoint of $200 \mathrm{ng} / \mathrm{ml}$ established by the AJCC and United Network for Organ Sharing (UNOS) for use in the clinical diagnosis of $\mathrm{HCC}^{14}$. The performance characteristics of total AFP and of AFP-L3\% for the diagnosis of HCC were determined using receiver operating characteristic (ROC) curves. The ROC curve is a plot of the sensitivity by 1 - specificity for any given AFP-L3\% or total AFP measurement. For a perfect marker, the sensitivity and the specificity are both $100 \%$. The optimal cutpoints for distinguishing between HCC and CLD were derived from the ROC curves. The sensitivity and specificity of AFP-L3\% for diagnosis of HCC were calculated for the entire group and also for the two subcategories of total AFP using different cut-points for AFP-L3\%. Because AFPL3\% was either unmeasurable or not reported in patients with a total AFP of $<10 \mathrm{ng} / \mathrm{ml}$, so as not to bias the performance towards total AFP, ROC curves for total AFP and AFP-L3\% were compared for patients with total AFP of $10-200 \mathrm{ng} / \mathrm{ml}$ and $10-=300,000 \mathrm{ng} / \mathrm{ml}$. For the ROC analyses, high (H) samples with a total AFP of $>300,000 \mathrm{ng} / \mathrm{ml}$ were assigned an AFP-L3\% value of $100 \%$.

The distributions of the AFP-L3\% by tumor grade, size, stage and vascular invasion were plotted with the three strata of total AFP. Kaplan-Meier survival curves were plotted for HCC patients comparing survival for patients with AFP-L3\% $=10 \%$ compared to $<10 \%$ (reference) and also for patients with total AFP $=200 \mathrm{ng} / \mathrm{ml}$ compared to $<200 \mathrm{ng} / \mathrm{ml}$ using the $\log$ rank test. The ratio of observed over expected deaths based on follow-up time was calculated for HCC patients with AFP-L3\% <10\% and $=10 \%$, within the three AFP strata. In bivariate and multivariate analyses, Cox proportional hazards models were used to estimate the hazard ratio of death for patients with an AFP-L3\% of $=10 \%$ (vs $<10 \%$ ), or with AFP-L3\% in the ranges of $10-35 \%$ and $>35 \%$ (vs. $<10 \%$ ).

\section{RESULTS}

\section{Patient characteristics}

The characteristics of the 272 study participants are presented in Table 1 . Of the 166 patients with HCC, 120 (72.3\%) had histologically proven HCC. HCC patients were significantly older $(\mathrm{p}<0.001)$, had a lower prevalence of cirrhosis $(\mathrm{p}=0.017)$ and had better hepatic function as shown by the laboratory data and MELD scores compared to CLD patients. In contrast, the 
median AFP and AFP-L3\% were significantly higher in HCC patients than in CLD patients $(\mathrm{p}<0.001$ and $\mathrm{p}<0.001$, respectively).

\section{Diagnostic utility of AFP-L3\% and absolute AFP-L3 in combination with AFP}

ROC curves for the diagnosis of HCC using AFP-L3\% and total AFP are shown in Figure 1A (total AFP of $10-300,000 \mathrm{ng} / \mathrm{ml}$ ) and 1B (total AFP of $10-200 \mathrm{ng} / \mathrm{ml}$ ). For the total AFP range of $10-300,000 \mathrm{ng} / \mathrm{ml}$, the maximum area under the curve (AUC) for distinguishing between HCC and CLD was 0.80 for AFP-L3\% and 0.78 for total AFP ( $\mathrm{p}=0.754)$. For the total AFP range of $10-200 \mathrm{ng} / \mathrm{ml}$, the AUC for diagnosis of HCC using AFP-L3\% was 0.76, almost significantly different from the AUC of 0.59 for total AFP ( $\mathrm{p}=0.074$ ). A scatter plot of the AFP-L3\% by total AFP for all patients is shown in Figure 2. Since the AFP-L3\% is typically not reported for an AFP $<10 \mathrm{ng} / \mathrm{ml}$, AFP-L3\% was not relevant for the diagnosis of HCC for individuals with a total AFP $<10 \mathrm{ng} / \mathrm{ml}$. On the other hand, all patients with a total AFP $>200$ $\mathrm{ng} / \mathrm{ml}$ had HCC, therefore the AFP-L3\% again provided no additional benefit for the diagnosis of HCC in these patients. Within the three strata, a small majority of HCC patients had a total AFP $<10 \mathrm{ng} / \mathrm{ml}(63 / 166 ; 38 \%), 52 / 166$ (31\%) had a total AFP 10-200 ng/ml, and 51/166 (31\%) had a total AFP $>200 \mathrm{ng} / \mathrm{ml}$. Sixty-nine percent (53/77) of CLD patients had an AFP <10 ng/ $\mathrm{ml}$, none (0/77) had a total AFP $>200 \mathrm{ng} / \mathrm{ml}$. All patients (29/29) with a benign liver mass had an AFP $<10 \mathrm{ng} / \mathrm{ml}$.

Fifty-two (68\%) of the 76 patients with total AFP $10-200 \mathrm{ng} / \mathrm{ml}$ had HCC, and the remaining $24(32 \%)$ had CLD. In this subset of patients, an AFP-L3\% >10\% was present in 71\% (37/52) of HCC patients versus $38 \%(9 / 24)$ of CLD patients $(\mathrm{p}=0.005)$. With the recommended AFPL3\% cutpoint of $=10 \%$, the sensitivity of the AFP-L3\% for HCC was $71 \%$ and the specificity was $63 \%$; with a cutpoint of $=35 \%$, the sensitivity was lower at $33 \%(17 / 52)$ but the specificity was $100 \%$ (24/24)(Table 2). Thus, in this subset of patients with a total AFP of 10-200 ng/ml, setting a high specificity cutpoint of AFP-L3\% $=35 \%$ would have led to the confident diagnosis of HCC in an additional $17(10 \%)$ of the $166 \mathrm{HCC}$ patients in the study. In addition, we explored the utility of the absolute concentration of AFP-L3 (AFP-L3\% $\times$ total AFP) for diagnosis of HCC. A $100 \%$ specificity absolute AFP-L3 cutpoint of $=11 \mathrm{ng} / \mathrm{ml}$ was equivalent to the AFPL3\% cutpoint of $35 \%$, allowing the diagnosis of $\mathrm{HCC}$ in 17 of the 52 patients with a total AFP of 10-200 ng/ml. Combining the high specificity AFP-L3\% and absolute AFP-L3 cutpoints allowed diagnosis of an additional $22(13 \%)$ of the 166 HCC patients, 5 more than would be diagnosed using either cutpoint alone.

\section{Relationship between AFP-L3\% and tumor characteristics}

We investigated the relationships between AFP-L3\% and tumor size, TNM stage, vascular invasion and histologic grade within the three AFP categories (Figure 3A-D). After adjusting for total AFP values, the distributions of the AFP-L3\% measurements demonstrated no independent association of AFP-L3\% with these characteristics. There was a slight trend of increasing AFP-L3\% with increasing TNM stage. Although the means were calculated without taking into consideration AFP-L3\% outlier values that were below the level of detection or were unreliable $(\mathrm{U}, \mathrm{ND}$, and $\mathrm{NR}$ ) or that could not be determined because of excessively high total AFP values $(\mathrm{H})$, these values were mostly in the category of AFP $<10 \mathrm{ng} / \mathrm{ml}$ and the missing values would have had little impact on the AFP 10-200 ng/ml and AFP > $200 \mathrm{ng} / \mathrm{ml}$ categories. However, it is still possible that the lack of association found was due to the relatively small numbers in each sub-category of the different prognostic variables.

\section{Survival in HCC patients}

Of the 165 HCC patients with survival data (vital status on 1 patient was not available), 86 patients had expired. Twenty-one of the 86 had total AFP values $<10 \mathrm{ng} / \mathrm{ml}$, leaving 65 in the total AFP $10-200 \mathrm{ng} / \mathrm{ml}$ and total AFP $>200 \mathrm{ng} / \mathrm{ml}$ categories. The ratio of observed/expected 
$(\mathrm{O} / \mathrm{E})$ number of deaths based on deaths during follow-up is shown in Table 3. Within total AFP strata, there was no difference in the O/E for AFP-L3\% $<10 \%$ and AFP-L3\% $=10 \%$. However, the $\mathrm{O} / \mathrm{E}$ was greater in $\mathrm{HCC}$ patients with total AFP $>200 \mathrm{ng} / \mathrm{ml}$ than in patients with total AFP 10-200 ng/ml, suggesting a greater likelihood of death among HCC patients with AFP $>200 \mathrm{ng} / \mathrm{ml}$. For patients with total AFP $>200 \mathrm{ng} / \mathrm{ml}$ and AFP-L3\% $=10 \%$, the O/E was significantly elevated $(\mathrm{O} / \mathrm{E}=2.11 ; 95 \% \mathrm{CI}=1.47,2.91)$. When all AFP categories were combined, the observed number of deaths (12) was equal to the expected (13.46) in patients with AFP-L3\% <10\% $(\mathrm{O} / \mathrm{E}$ ratio $=0.89 ; 95 \% \mathrm{CI}=0.46,1.56)$, but the observed number of deaths (53) was greater than the expected (38.13) among patients with AFP-L3\% $=10 \%(\mathrm{O} / \mathrm{E}$ $=1.39 ; 95 \% \mathrm{CI}=1.04,1.82)$. This showed a better survival for patients with AFP-L3\%<10\% (81\% 1-year survival; 62\% 4-year survival) than for patients with AFP-L3\% $=10 \%(63 \% 1$ year survival; 35\% 4-year survival) as shown in the survival curves in Figure 4A ( $\mathrm{p}=0.0012$ using the log rank test). However, the total AFP is an even better predictor of survival; patients with a total AFP $<200 \mathrm{ng} / \mathrm{ml}$ having a better survival (81\% 1-year survival; 63\% 4-year survival) than patients with a total AFP $>200 \mathrm{ng} / \mathrm{ml}$ (53\% 1-year survival; 20\% 4-year survival) (Figure 4B; $\mathrm{p}<0.0001$ ). After adjustment for total AFP, the O/E ratio was nearly 1 for both AFP-L3\% <10\% $(0.9,95 \% \mathrm{CI}=0.45,1.53)$ and AFP-L3\% $=10 \%(1.0 ; 95 \% \mathrm{CI}=0.77,1.35)$, suggesting no association of AFP-L3\% with mortality once the level of total AFP is taken into account (Table 3). With adjustment for potential confounders (MELD score, tumor grade, size, and vascular involvement), the estimates were unchanged.

\section{DISCUSSION}

Mortality rates for HCC have significantly increased worldwide and in the United States during the past two decades. Regular follow-up of chronic liver disease patients is indispensable for early detection of HCC ${ }^{15}$. Although serum AFP has been a routine marker for diagnosing HCC, mild elevation of AFP also occurs in viral hepatitis and other liver diseases 16, 17 . The detection rates for small HCCs by AFP measurement are low (5.6-17.6\%) at a high-specificity cut-off of $200 \mathrm{ng} / \mathrm{ml} 18-20$. Recently, AFP-L3\% has been introduced as a new tumor marker with reportedly higher detection rates for small HCCs $(17.2-28.2 \%) 6,21$. In this study, when we used the standard cut-off of AFP-L3\% at 10\% to determine the utility of this tumor marker, the sensitivity and specificity for detection of all HCCs were $48 \%$ and $88 \%$, respectively.

However, most of the patients with elevated AFP-L3\% would have triggered further evaluation by virtue of having a high total AFP. We therefore explored the additional utility of AFP-L3\% given a known AFP value. The group of patients with total AFP values in the intermediate $10-200 \mathrm{ng} / \mathrm{ml}$ range, frequently individuals with chronic hepatitis $\mathrm{C}$ virus infection, often presents a diagnostic dilemma, as they often have false-positive elevations of total AFP. In much the same way that an alternate cut-off of 200-400 $\mathrm{ng} / \mathrm{ml}$ of total AFP is used in practice (because it affords a high specificity in the diagnosis of HCC), we found that a cut-off of AFPL3\% of 35\% appears to afford a similar high specificity. In the cohort of patients we examined, for individuals with an indeterminate total AFP level in the intermediate range of 10-200 ng/ $\mathrm{ml}$, an AFP-L3\% cut-off of 35\% resulted in the inclusion of an additional 17 patients $(10 \%)$ in the HCC category with a high specificity of $100 \%$ (Figure 2). Thus, an AFP-L3\% cut off of $35 \%$ can be used as an adjunct for the diagnosis of $\mathrm{HCC}$ in patients with intermediate range total AFP values by identifying those who do have HCC, and thereby targeting efforts and resources for confirmation of $\mathrm{HCC}$ on those patients most likely to have HCC. Further, although the use of a high specificity absolute AFP-L3 concentration cut off of $11 \mathrm{ng} / \mathrm{ml}$ was not better than the use of the AFP-L3\%, use of this cut off allowed identification of an additional $5 \mathrm{HCC}$ patients beyond those identified using the AFP-L3\% cut off of 35\%. Hence, it is possible to design a combined algorithm using high specificity cut offs of total AFP, AFP-L3\% and absolute AFP-L3 to achieve the best test performance. Previously reported prospective studies have shown that the elevation in AFP-L3\% occurs earlier than the elevation in total AFP concentration in HCC patients 7,16 . Due to the retrospective ascertainment of data for the 
present study, however, serum was only available at the time of diagnosis, and the temporal association between total AFP and AFP-L3\% could not be evaluated.

According to previous reports, positivity for AFP-L3\% may be an unfavorable prognostic factor in patients with $\mathrm{HCC} 22,23$. Oka et al have demonstrated that the characteristics of having an advanced tumor, including the number of tumors, maximum diameter, tumor spread, portal vein invasion, tumor stage, and tumor classification, were associated with a positive AFP-L3\% in HCC patients (cut-off at 10\%) 24 . The total AFP value has also been associated with many of the same prognostic features. In the present study, once the total AFP value was taken into account, we observed no association between the distribution of AFP-L3\% and tumor size, stage, vascular invasion or histologic grade. This is consistent with the results of other authors $10,25,26$. The differences in prognostic factors noted in some studies may be related to differences in the underlying etiology and biology of the HCC patients enrolled. The majority of patients in our study population underwent liver transplantation, whereas most of the other studies reported are from countries with lower rates of liver transplantation, where patients are more likely to be treated by surgical resection, local ablation, transcatheter arterial chemoembolization (TACE) or other palliative therapy.

It has been reported that AFP-L3\%-positive patients have significantly lower overall survival than patients with negative AFP-L3\%. Our study showed no difference in hazard of death in patients with AFP-L3\% $=10 \%$ compared to AFP-L3\% <10\% after adjustment for AFP. This discrepancy is most likely because a number of the previously reported studies did not adjust for total AFP, however, our study may also have had inadequate power to detect a small but statistically significant difference.

In conclusion, our data suggest that the determination of AFP-L3\%, in combination with AFP, increases the specificity of diagnosis of HCC in individuals with indeterminate elevations of total AFP (10-200 ng/ml). Thus, the AFP-L3\% should be useful as an adjunctive marker, in combination with AFP, to confirm the diagnosis of HCC. However, we observed no prognostic significance for AFP-L3\% after adjustment for total AFP.

\section{Acknowledgements}

This study was funded by grants from Wako Chemical USA, Mayo Clinic and Mayo Cancer Center, by NIH Grants CA82862 and CA100882, an Industry Research Scholar Award from the Foundation for Digestive Health and Nutrition, a Harold Amos Medical Faculty Development Award from The Robert Wood Johnson Foundation, a generous gift from The Richard M. Schulze Family Foundation and by the Miles and Shirley Fiterman Center for Digestive Diseases at the Mayo Clinic, Rochester, MN (to L.R.R.). The authors thank Drs. Chiranjeev Dash and Arvind Reddy for assistance with data abstraction, Dr. Ruben Bonilla Guerrero and Michelle Andersen for assistance with figures, and Stacy Roberson and Erin Bungum for secretarial assistance.

\section{References}

1. El-Serag HB, Davila JA, Petersen NJ, McGlynn KA. The continuing increase in the incidence of hepatocellular carcinoma in the United States: an update. Ann Intern Med 2003;139:817-23. [PubMed: 14623619]

2. El-Serag HB, Mason AC, Key C. Trends in survival of patients with hepatocellular carcinoma between 1977 and 1996 in the United States. Hepatology 2001;33:62-5. [PubMed: 11124821]

3. El-Serag HB, Siegel AB, Davila JA, Shaib YH, Cayton-Woody M, McBride R, McGlynn KA. Treatment and outcomes of treating of hepatocellular carcinoma among Medicare recipients in the United States: a population-based study. J Hepatol 2006;44:158-66. [PubMed: 16290309]

4. Hayashi K, Kumada T, Nakano S, Takeda I, Sugiyama K, Kiriyama S, Sone Y, Miyata A, Shimizu H, Satomura S. Usefulness of measurement of Lens culinaris agglutinin-reactive fraction of alphafetoprotein as a marker of prognosis and recurrence of small hepatocellular carcinoma. Am J Gastroenterol 1999;94:3028-33. [PubMed: 10520864] 
5. Okuda K, Tanaka M, Kanazawa N, Nagashima J, Satomura S, Kinoshita H, Eriguchi N, Aoyagi S, Kojiro M. Evaluation of curability and prediction of prognosis after surgical treatment for hepatocellular carcinoma by lens culinaris agglutinin-reactive alpha-fetoprotein. Int J Oncol 1999;14:265-71. [PubMed: 9917501]

6. Shiraki K, Takase K, Tameda Y, Hamada M, Kosaka Y, Nakano T. A clinical study of lectin-reactive alpha-fetoprotein as an early indicator of hepatocellular carcinoma in the follow-up of cirrhotic patients. Hepatology 1995;22:802-7. [PubMed: 7544756]

7. Taketa K, Endo Y, Sekiya C, Tanikawa K, Koji T, Taga H, Satomura S, Matsuura S, Kawai T, Hirai H. A collaborative study for the evaluation of lectin-reactive alpha-fetoproteins in early detection of hepatocellular carcinoma . Cancer Res 1993;53:5419-23. [PubMed: 7693340]

8. Yamashita F, Tanaka M, Satomura S, Tanikawa K. Prognostic significance of Lens culinaris agglutinin A-reactive alpha-fetoprotein in small hepatocellular carcinomas. Gastroenterology 1996;111:9961001. [PubMed: 8831594]

9. Hirai Y, Waki II, Momose A, Fukazawa T, Aida T, Takagi K, Hirano T. Increase of O 2p unoccupied electronic states within the ab plane of $\mathrm{YBa} 2 \mathrm{Cu} 3 \mathrm{O} 6.8$ due to a superconducting transition. Physical Review B Condensed Matter 1992;45:2573-2576.

10. Song BC, Suh DJ, Yang SH, Lee HC, Chung YH, Sung KB, Lee YS. Lens culinaris agglutinin-reactive alpha-fetoprotein as a prognostic marker in patients with hepatocellular carcinoma undergoing transcatheter arterial chemoembolization. J Clin Gastroenterol 2002;35:398-402. [PubMed: 12394228]

11. Kamath PS, Wiesner RH, Malinchoc M, Kremers W, Therneau TM, Kosberg CL, D'Amico G, Dickson ER, Kim WR. A model to predict survival in patients with end-stage liver disease. Hepatology 2001;33:464-70. [PubMed: 11172350]

12. Yamagata Y, Shimizu K, Nakamura K, Henmi F, Satomura S, Matsuura S, Tanaka M. Simultaneous determination of percentage of Lens culinaris agglutinin-reactive alpha-fetoprotein and alphafetoprotein concentration using the LiBASys clinical auto-analyzer. Clin Chim Acta 2003;327:5967. [PubMed: 12482619]

13. Marrero JA, Su GL, Wei W, Emick D, Conjeevaram HS, Fontana RJ, Lok AS. Des-gamma carboxyprothrombin can differentiate hepatocellular carcinoma from nonmalignant chronic liver disease in american patients. Hepatology 2003;37:1114-21. [PubMed: 12717392]

14. Committee OULaIOT. Modifications to the policy 3.6.4.4 (Liver Transplant Candidates with Hepatocellular Carcinoma). November 19;2004

15. Shimauchi Y, Tanaka M, Kuromatsu R, Ogata R, Tateishi Y, Itano S, Ono N, Yutani S, Nagamatsu H, Matsugaki S, Yamasaki S, Tanikawa K, Sata M. A simultaneous monitoring of Lens culinaris agglutinin A-reactive alpha-fetoprotein and des-gamma-carboxy prothrombin as an early diagnosis of hepatocellular carcinoma in the follow-up of cirrhotic patients. Oncol Rep 2000;7:249-56. [PubMed: 10671666]

16. Sato Y, Nakata K, Kato Y, Shima M, Ishii N, Koji T, Taketa K, Endo Y, Nagataki S. Early recognition of hepatocellular carcinoma based on altered profiles of alpha-fetoprotein. N Engl J Med 1993;328:1802-6. [PubMed: 7684823]

17. Hu KQ, Kyulo NL, Lim N, Elhazin B, Hillebrand DJ, Bock T. Clinical significance of elevated alphafetoprotein (AFP) in patients with chronic hepatitis C, but not hepatocellular carcinoma. Am J Gastroenterol 2004;99:860-5. [PubMed: 15128351]

18. Tsai SL, Huang GT, Yang PM, Sheu JC, Sung JL, Chen DS. Plasma des-gamma-carboxyprothrombin in the early stage of hepatocellular carcinoma. Hepatology 1990;11:481-8. [PubMed: 2155866]

19. Izuno K, Fujiyama S, Yamasaki K, Sato M, Sato T. Early detection of hepatocellular carcinoma associated with cirrhosis by combined assay of des-gamma-carboxy prothrombin and alphafetoprotein: a prospective study. Hepatogastroenterology 1995;42:387-93. [PubMed: 8586374]

20. Nomura F, Ishijima M, Horikoshi A, Nakai T, Ohnishi K. Determination of serum des-gammacarboxy prothrombin levels in patients with small-sized hepatocellular carcinoma: comparison of the conventional enzyme immunoassay and two modified methods. Am J Gastroenterol 1996;91:13803. [PubMed: 8677999] 
21. Kuromatsu R, Tanaka M, Tanikawa K. Serum alpha-fetoprotein and lens culinaris agglutinin-reactive fraction of alpha-fetoprotein in patients with hepatocellular carcinoma. Liver 1993;13:177-82. [PubMed: 7690873]

22. Aoyagi Y, Mita Y, Suda T, Kawai K, Kuroiwa T, Igarashi M, Kobayashi M, Waguri N, Asakura H. The fucosylation index of serum alpha-fetoprotein as useful prognostic factor in patients with hepatocellular carcinoma in special reference to chronological changes. Hepatol Res 2002;23:287. [PubMed: 12191676]

23. Kusaba T. Relationship between Lens culinaris agglutinin reactive alpha-fetoprotein and biological features of hepatocellular carcinoma. Kurume Med J 1998;45:113-20. [PubMed: 9658760]

24. Oka H, Saito A, Ito K, Kumada T, Satomura S, Kasugai H, Osaki Y, Seki T, Kudo M, Tanaka M. Multicenter prospective analysis of newly diagnosed hepatocellular carcinoma with respect to the percentage of Lens culinaris agglutinin-reactive alpha-fetoprotein. J Gastroenterol Hepatol 2001;16:1378-83. [PubMed: 11851836]

25. Kumada T, Nakano S, Takeda I, Kiriyama S, Sone Y, Hayashi K, Katoh H, Endoh T, Sassa T, Satomura S. Clinical utility of Lens culinaris agglutinin-reactive alpha-fetoprotein in small hepatocellular carcinoma: special reference to imaging diagnosis. J Hepatol 1999;30:125-30. [PubMed: 9927159]

26. Sassa T, Kumada T, Nakano S, Uematsu T. Clinical utility of simultaneous measurement of serum high-sensitivity des-gamma-carboxy prothrombin and Lens culinaris agglutinin A-reactive alphafetoprotein in patients with small hepatocellular carcinoma. Eur J Gastroenterol Hepatol 1999;11:1387-92. [PubMed: 10654799] 


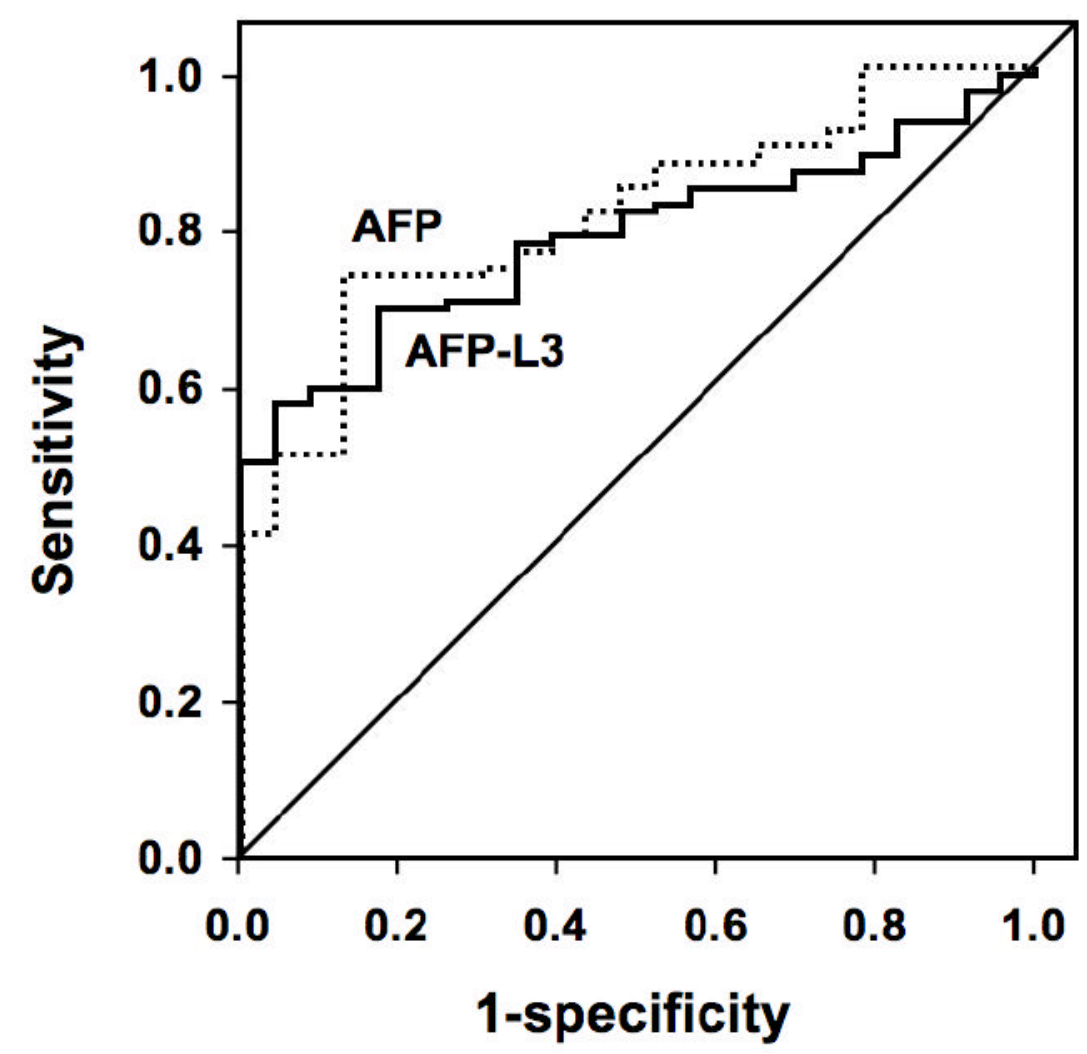




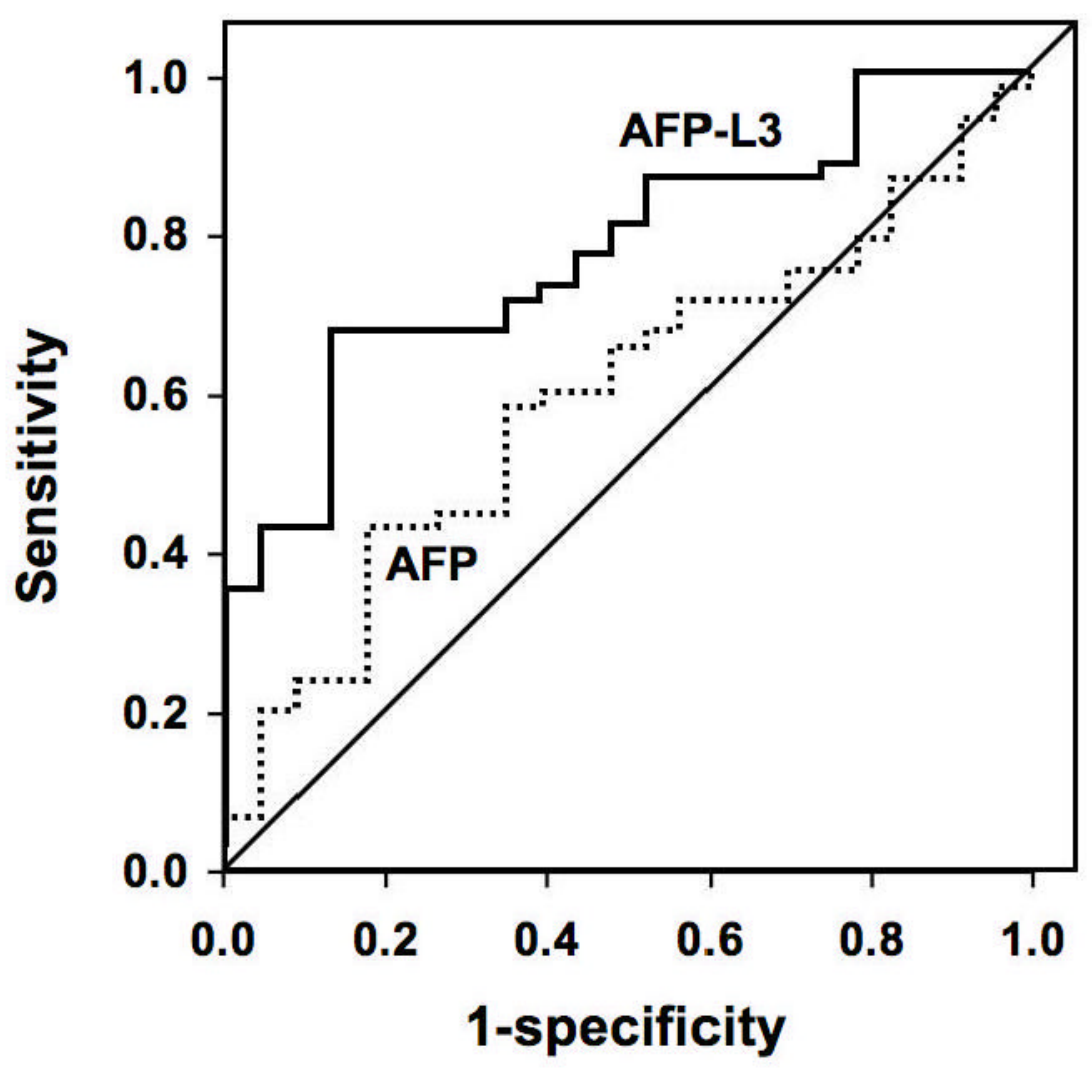

Figure 1.

Figure 1A. Receiver operating characteristic (ROC) curves comparing total AFP with AFP$\mathrm{L} 3 \%$ for diagnosis of HCC in individuals with total AFP greater than $10 \mathrm{ng} / \mathrm{ml}$.

Figure 1B. ROC curves comparing total AFP with AFP-L3\% for diagnosis of HCC in individuals with total AFP between 10 and $200 \mathrm{ng} / \mathrm{ml}$. 


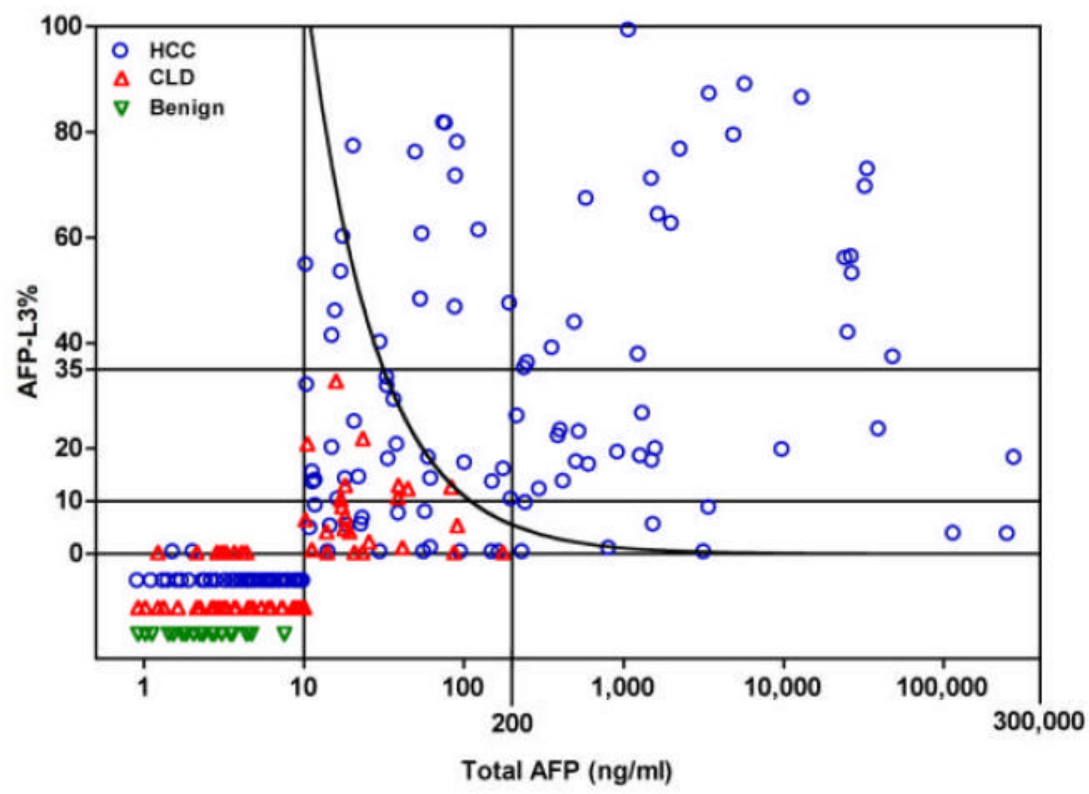

Figure 2. Scatter plot of AFP-L3 by AFP category

For individuals with a total AFP in the indeterminate range of 10-200 ng/ml, an AFP-L3\% of greater than $35 \%$ was $100 \%$ specific, with no false positives. The curved line represents an absolute AFP-L3 cut-off value of $11 \mathrm{ng} / \mathrm{ml}$, which was also 100\% specific. NR: AFP-L3 values are non-specific and not reported when total AFP is in the range $0.8-10 \mathrm{ng} / \mathrm{ml}$ and AFP-L3 is $>0.5 \%$. 

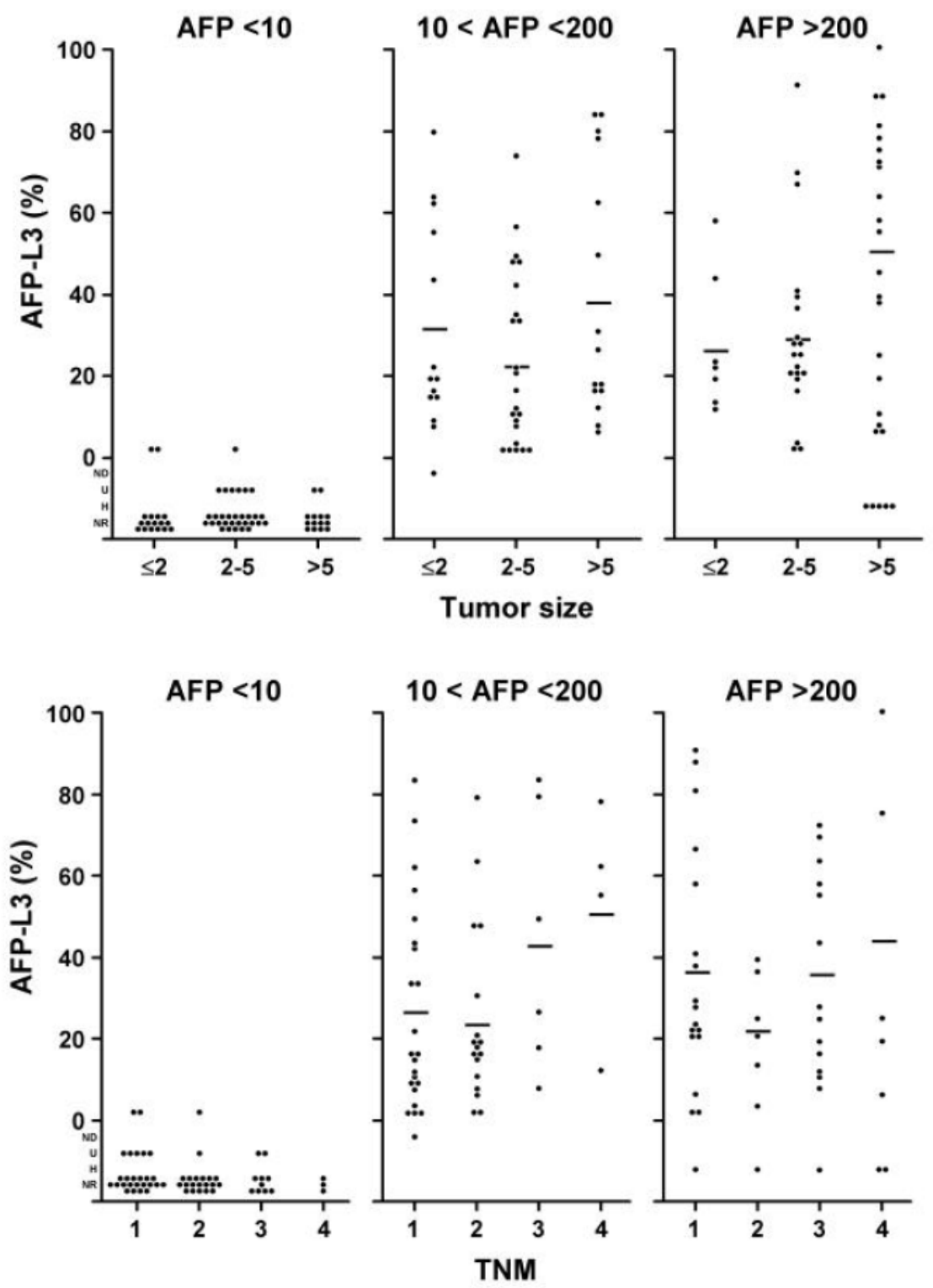

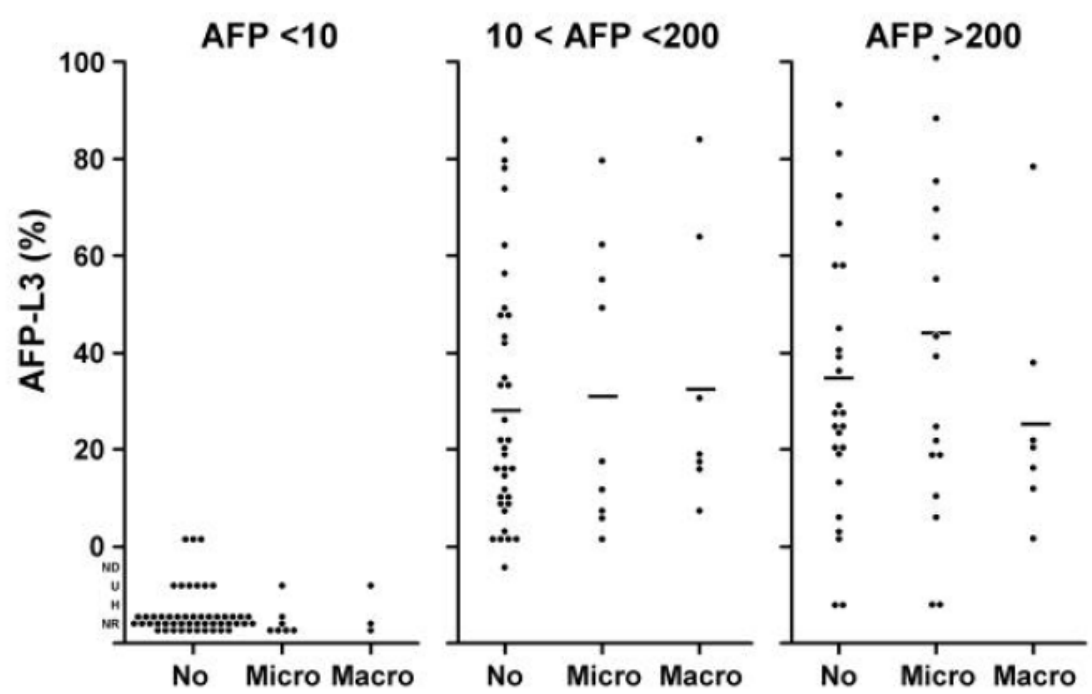

\section{Vascular involvement}
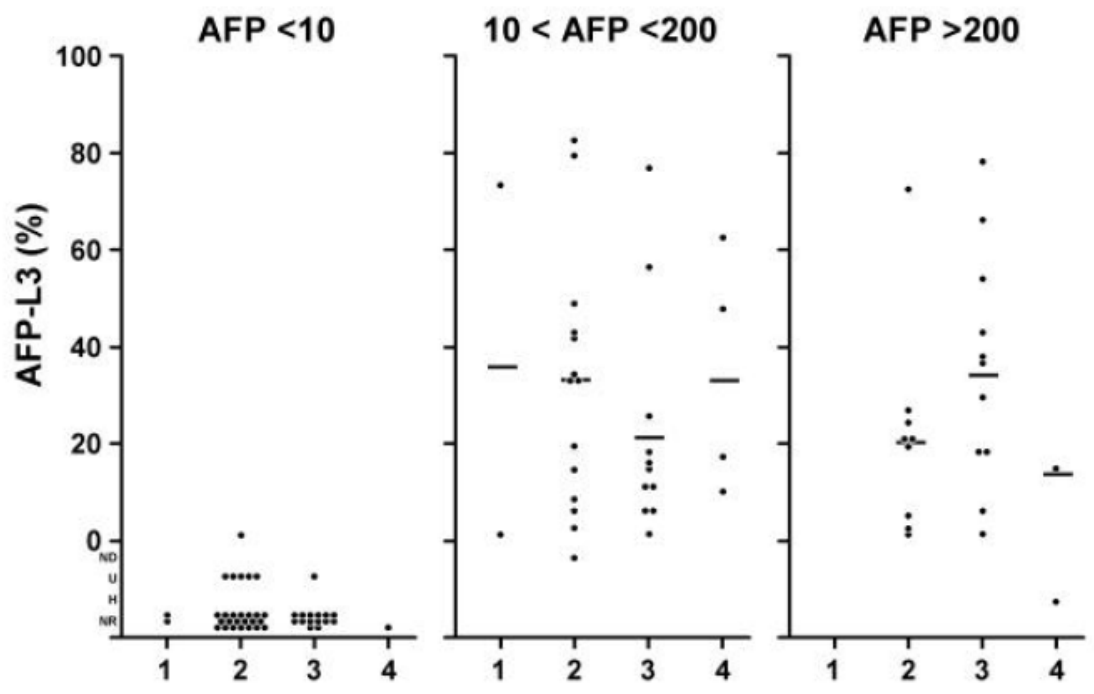

Tumor Grade

Figure 3. Distribution of AFP-L3 level by tumor characteristics

Histograms showing the relationship between AFP-L3\% and tumor characteristics: $3 \mathrm{~A}$, tumor size; 3B, tumor stage; 3C, vascular invasion; and 3D, histologic grade. The means were calculated without taking into consideration AFP-L3 values which were not detected (ND), not reported (NR), not measurable because the total AFP was undetected (U), or not measurable because the total AFP was $>300,000 \mathrm{ng} / \mathrm{ml}(\mathrm{H})$. There is little effect of L3\% for tumor size, tumor grade, and vascular involvement. There is a possible trend for TNM, but the numbers are small. 

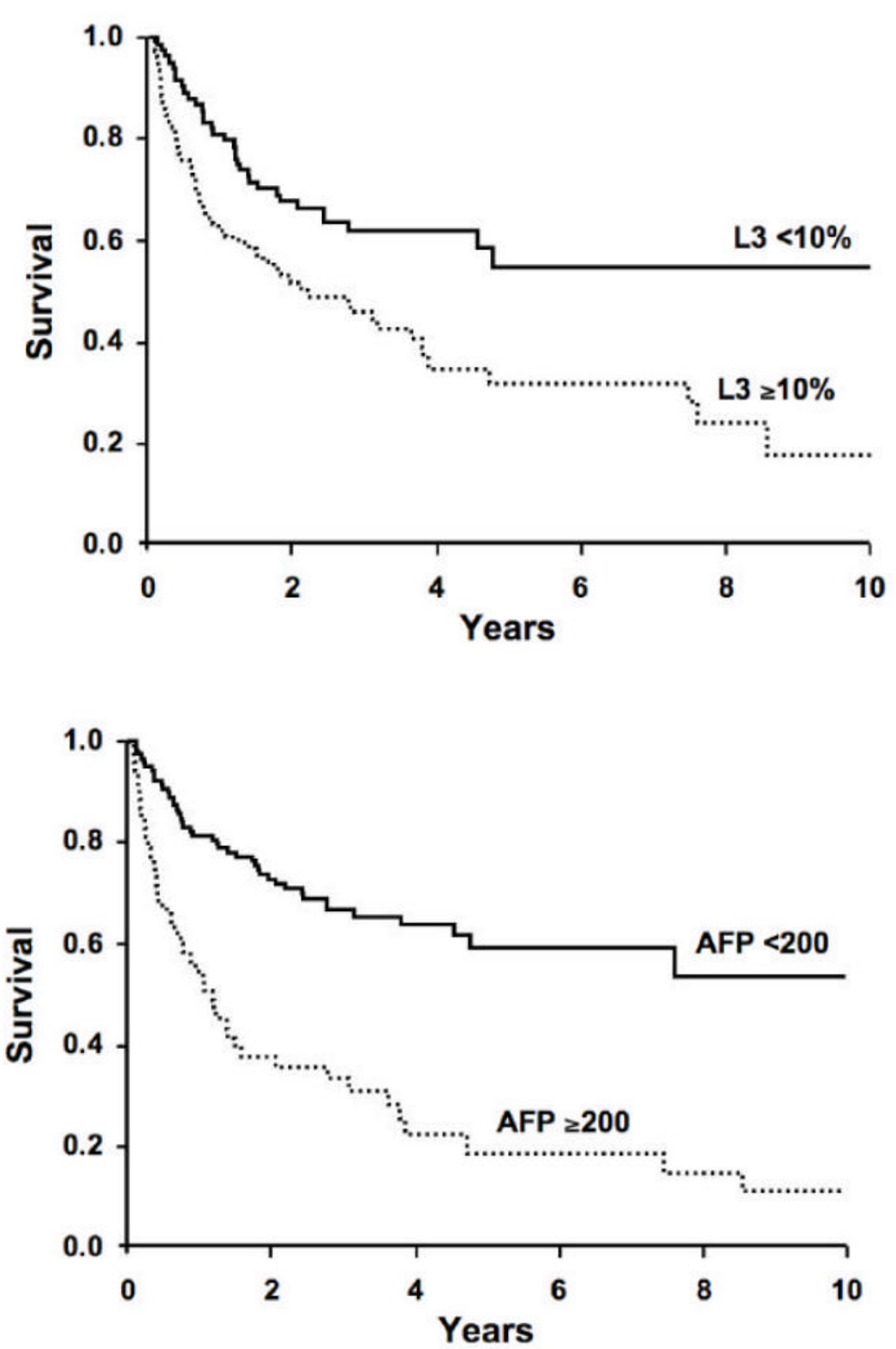

Figure 4. Survival in hepatocellular carcinoma patients by AFP-L3\% level and total AFP level 4A: AFP-L3\% level > 10\% predicts survival of patients with HCC $(\mathrm{p}=0.0012)$. 4B: Total AFP $>200 \mathrm{ng} / \mathrm{ml}$ is a better predictor of survival of HCC patients $(\mathrm{p}<0.0001)$. Once total AFP is taken into account, there is no additional prognostic value of the AFP-L3\% in this cohort. 
Table 1

Clinical characteristics of study participants at the time of diagnosis

\begin{tabular}{|c|c|c|c|c|}
\hline \multicolumn{5}{|c|}{ Patient Characteristics } \\
\hline HCC & CLD & P-Value & Benign \\
\hline Male gender (n, \%) & 166 & 77 & & 29 \\
\hline Age (median, range) & $120(72 \%)$ & $54(70 \%)$ & 0.846 & $6(21 \%)$ \\
\hline Cirrhosis (n, \%) & $60.5(32-89)$ & $46(18-74)$ & $<0.001$ & $51(20-73)$ \\
\hline Hepatitis Status & $134(81 \%)$ & $72(94 \%)$ & 0.017 & $1(3 \%)$ \\
\hline HBsAg+ Anti-HCV+ & 0 & & & 0 \\
\hline HBsAg- Anti-HCV+ & 58 & 0 & & 0 \\
\hline HBsAg+ Anti-HCV- & 11 & 60 & & 0 \\
\hline HBsAg- Anti-HCV- & 77 & 3 & & 26 \\
\hline Laboratory Findings (median, range) & 9 & & $4.2(2.6-4.8)$ \\
\hline Albumin & $3.5(1.5-4.7)$ & $3.1(1.1-4.5)$ & $<0.001$ & $0.5(0.3-2.9)$ \\
\hline Total bilirubin & $1.4(0.3-11.5)$ & $2.6(0.3-47)$ & $<0.001$ & $9.3(8.5-12.6)$ \\
\hline PT & $10.6(8.2-18.9)$ & $12.55(8.7-25)$ & $<0.001$ & $251(59-578)$ \\
\hline Platelet Count & $135(9-819)$ & $71.5(31-367)$ & $<0.001$ & $22(11-141)$ \\
\hline ALT & $62(12-948)$ & $78(11-811)$ & 0.015 & $6(6-12)$ \\
\hline MELD & $10(6-20)$ & $13(6-31)$ & $<0.001$ & $1.7(0.8-7.4)$ \\
\hline AFP & $28(0.8->300,000)$ & $7.5(1.5-110)$ & $<0.001$ & NA (NA - NA) \\
\hline AFP-L3\% & $25.75(1.2-99.5)$ & $9.85(1-33)$ & $<0.001$ & 0 \\
\hline ND & 11 & 17 & & 0 \\
\hline H & 5 & 0 & & 22 \\
\hline NR & 52 & 36 & & 7 \\
\hline U & 8 & 5 & \\
\hline
\end{tabular}

Missing data: Hepatitis status $-20 \mathrm{HCC}$ and 5 CLD patients

$\mathrm{ND}$ (not detected): total AFP $=10 \mathrm{ng} / \mathrm{ml}$ and AFP-L3 $<0.5 \%$

NR (not reported): $0.8<$ total AFP $<10 \mathrm{ng} / \mathrm{ml}$ and AFP-L3 $>0.5 \%$

$\mathrm{U}$ (unmeasurable): total AFP $<0.8 \mathrm{ng} / \mathrm{ml}$

$\mathrm{H}$ (high): total AFP $>300,000 \mathrm{ng} / \mathrm{ml}$.

HCC, hepatocellular carcinoma; CLD, chronic liver disease; HBsAg, hepatitis B surface antigen; Anti-HCV, antibody to hepatitis C virus; PT, prothrombin time; ALT, alanine aminotransferase; MELD, model for end-stage liver disease score; AFP, alpha fetoprotein. 
Table 2

Performance of AFP-L3\% in individuals with total AFP of 10-200 ng/ml

\begin{tabular}{ccc}
\hline AFP-L3\% & Sensitivity & Specificity \\
\hline$=10 \%$ & $71 \%$ & $63 \%$ \\
$=35 \%$ & $33 \%$ & $100 \%$ \\
\hline
\end{tabular}


Table 3

Survival characteristics of hepatocellular carcinoma patients by AFP-L3\%

\begin{tabular}{|c|c|c|c|}
\hline \multirow[t]{2}{*}{ Variable } & \multicolumn{3}{|c|}{ AFP-L3 (\%) } \\
\hline & $<10(n=85)$ & $=10(n=80)$ & Total \\
\hline \multicolumn{4}{|l|}{ Total AFP 10-200 (ng/ml) } \\
\hline Number of Subjects & 15 & 37 & 52 \\
\hline Observed Deaths & 6 & 17 & 23 \\
\hline Expected Deaths & 10.44 & 21.03 & 31.48 \\
\hline $\mathrm{O} / \mathrm{E}$ ratio $(95 \% \mathrm{CI})$ & $0.57(0.21-1.25)$ & $0.81(0.47-1.29)$ & $0.73(0.46-1.10)$ \\
\hline \multicolumn{4}{|l|}{ Total AFP >200 (ng/ml) } \\
\hline Number of Subjects & 8 & 43 & 51 \\
\hline Observed Deaths & 6 & 36 & 42 \\
\hline Expected Deaths & 3.01 & 17.10 & 20.11 \\
\hline O/E ratio ( $95 \%$ CI) & $1.99(0.73-4.33)$ & $2.11(1.47-2.91)$ & $2.09(1.50-2.82)$ \\
\hline \multicolumn{4}{|l|}{ All HCC with AFP = $10(\mathrm{ng} / \mathrm{ml})$} \\
\hline Number of Subjects & 23 & 80 & 103 \\
\hline Observed Deaths & 12 & 53 & 65 \\
\hline Expected Deaths & 13.46 & 38.13 & 51.59 \\
\hline $\mathrm{O} / \mathrm{E}$ ratio $^{\dagger}(95 \% \mathrm{CI})$ & $0.89(0.46-1.56)$ & $1.39(1.04-1.82)$ & $2.28(0.97-1.61)$ \\
\hline $\begin{array}{c}\text { Expected Deaths Adj. AFP } \\
\text { O/E ratio (95\% CI) }\end{array}$ & $\begin{array}{l}13.74 \\
0.9(0.45-1.53)\end{array}$ & $\begin{array}{l}51.26 \\
1(0.77-1.35)\end{array}$ & \\
\hline
\end{tabular}

* Expected deaths estimated from the number of deaths during follow-up

$\dagger$ The model chi squares for the analyses stratified by total AFP were not significant, thus the analyses performed were for the combined AFP groups

O/E observed/expected ratio. 